\title{
New Insight Into the Mechanism of the Inhibition of Corrosion of Mild Steel by Some Amino Acids
}

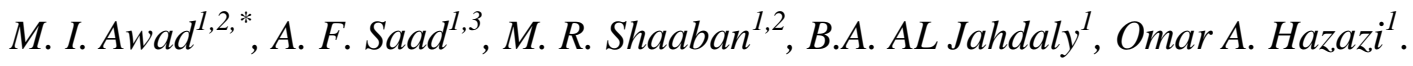 \\ ${ }^{1}$ Chemistry Department, Faculty of Applied Sciences, Umm Al-Qura University, Makkah Al- \\ Mukarramah, Saudi Arabia \\ ${ }^{2}$ Department of Chemistry, Faculty of Science, Cairo University, Cairo, Egypt \\ ${ }^{3}$ Chemistry Department, Faculty of Science, Assiut University, Assiut, 71516 Egypt. \\ *E-mail: $\underline{\text { mawad70@yahoo.com }}$
}

doi: $10.20964 / 2017.02 .300$

Received: 30 October 2016 / Accepted: 19 December 2016 / Published: 30 December 2016

The inhibition of the corrosion of mild steel in $0.5 \mathrm{M} \mathrm{H}_{2} \mathrm{SO}_{4}$ by vanillin in the presence of various amino acids, typically valine, methionine, cysteine and methylcysteine hydrochloride, are studied using potentiodynamic technique aiming at the elucidation of the mechanism of the corrosion inhibition. The corrosion inhibition of vanillin and amino acids was evaluated, both in their individual presence and in their coexistence. The largest inhibition efficiency has been found in the presence of vanillin and cysteine mixture. To have an insight into the mechanism of the inhibition and probe the adsorption sites of the inhibitor, the inhibition efficiency of a Schiff base, synthesized from vanillin and a selected amino acid, typically cysteine, has been compared with the inhibition efficiency of the vanillin and cysteine mixture. Interestingly, it has been found that the inhibition efficiency of the vanillin and cysteine mixture is much larger than the relevant Schiff base, and that the inhibition efficiency of the latter is much smaller than the inhibition efficiency in the presence of the individual components, i.e., vanillin and cysteine. This points to the blocking of the probable adsorption sites, upon the formation of Schiff base, which is the amino group of cysteine and the aldehydic group of vanillin. The adsorption of the methylcysteine, as an example, in the presence of vanillin was found to follow Temkin isotherm and that the chemical adsorption mode is controlling as revealed from the free energy of adsorption $(44.4 \mathrm{~kJ} / \mathrm{mol})$.

Keywords: Adsorption, Eco-friendly corrosion inhibitor, Synergism, Adsorption, Amino acids

\section{FULL TEXT}

(C) 2017 The Authors. Published by ESG (www.electrochemsci.org). This article is an open access article distributed under the terms and conditions of the Creative Commons Attribution license (http://creativecommons.org/licenses/by/4.0/). 